\title{
The Level of Psychological Burnout of Vocational Education Teachers Compared to Ordinary Teachers in Jordan
}

\author{
Elham Mahmoud Rababa ${ }^{\text {iD }}$ and Mohammad Omar AL-Momani ${ }^{2 *}$ iD \\ ${ }^{1}$ Ph.D. in Psychological and Educational Counseling \\ ${ }^{2}$ Educational Sciences Department, Ajloun University College, Al-Balqa Applied University, Jordan \\ "m.o.e.m@bau.edu.jo (Corresponding Author)
}

\section{ARTICLE INFORMATION}

Received: April 22, 2021

Revised: June 14, 2021

Accepted: August 02, 2021

Published Online: September 29, 2021

Keywords:

Burnout, Professional education teachers,

Ordinary teachers

DOI: $10.15415 /$ iie.2021.92011

\section{ABSTRACT}

The purpose of this study was to determine the psychological level of combustion of education teachers' professional compared to ordinary teachers in Jordan, with a sample size of 160 teachers including (80) vocational education teachers (40) males and (40) females, and (80) teachers and teachers ordinary (40) males and (40) females in the classroom semester first of the academic year (2019-2020). And, in order to achieve the objectives of the study, the two researchers devised a study tool, which is a measure of psychological burn out appropriate for the purposes of the study. As the result of the study, after conducting the necessary statistical treatment, it was observed that there were statistically significant variations in the level of psychological burnout between vocational educators and conventional teachers, favoring vocational educators.

\section{Introduction}

Interest is growing in the field of vocational education, which contributes to the provision of educational, social, and economic services to individuals, as this interest aids in the achievement of principles such as education for all, equal opportunities, human rights, community participation, and social justice, and has assisted in the acquisition of skills that were previously unattainable.

But with all this attention, this group did not get the highlight and attention to it like the rest of the other groups In terms of the psychological side and the psychological issues and pressures they encounter, which has been proven via research that have an impact on an individual's achievement and competence in critical vocations in society, such as teaching. As the focus has shifted to vocational education teachers in the field of continuously raising the level of their competencies and since educational institutions and schools are considered among the most important educational facilities due to the great role they play in investing human energies, and the teachers of vocational education are the important pillars of this institution and for various reasons that standout obstacles that prevent the teacher from fully carrying out his role, which contributes to his sense of inability to do his duty at the level expected of him. Others, and if this happened, the relationship between the teacher and his student takes a negative dimension that has devastating effects on the entire educational process. This sense of helplessness with the exhaustion of effort leads to a state of exhaustion and psychological burnout.

As a result, there is a need to raise awareness about psychological burnout, which is one of the consequences of serious psychological crises on human cadres working in educational institutions in general, and which has a negative impact on the social, health, and psychological aspects of those who suffer from it and are expected to carry out their work in distinctive ways (Al-Jamali, 2019; Najeeb, 2017; Al-Musharraf, 2019; Zaghoul, 2019; Al-Shuyoukh, 2016). 
Because of the importance of this topic, a number of studies have been published on it, such as Al-Qaryouti and Al-Khatib's (2018) study, which aimed to identify psychological burnout in a sample of Jordanian teachers of ordinary students and people with special needs, based on differences in student category, gender, monthly income, and marital status. As a result, there were no statistically significant variations in the degree of psychological burnout caused by gender or marital status. In addition to the presence of statistically significant variations in the variable of the teacher's specialisation, there were statistically significant disparities in the variable of income. As for the study of the Zahrani study (2018), which aimed to know the nature of the relationship between burnout and some personality traits, as the results of the study found an inverse correlation between psychological burnout and some personality traits in addition to the absence of statistically significant differences between the highs and lows of psychological burnout; The study of Al-Rafei and Al-Qudah (2019), which aimed to identify the levels of psychological burnout among faculty members in the Teachers College in Abha in light of the variables of age, academic qualification, specialization, experience in teaching, nationality, marital status, income level, number of students and teaching quorum. The results of the study concluded that the level of burnout the psychological level of the teaching staff was of a medium degree in addition to the presence of statistically significant differences according to the teaching quorum variable and in favor of the teaching quorum more in addition to the presence of statistically significant differences according to other variables.

\section{Study Problem}

In many professions of a humanitarian and cooperative nature, various obstacles and pressures appear that prevent the employee from performing his required role as he expects or as others expect (Al-Hamar, 2018; Al- Dairy, 2017; Al-Rashidi, 2018; Al-Sheikh, 2017; Issa, 2015). of the most prominent obstacles that may appear in the field of working teaching vocational education material and due to the lack of comparative studies in the limits of science researcher conducted the education teachers class professional compared to the category of teachers and ordinary in the detection of the psychological level of combustion have ArtaZ researchers to the need to look into this problem which plays an important role in the field of work in teaching vocational education.

\section{Objectives of the Study}

The study aims to detect the current psychological level of the combustion of the sample of education teachers professional headquarters $\mathrm{NH}$ ordinary teachers in the province of Jordan.

\section{Study Importance}

The importance of this study stems from the importance of the role played by vocational education teachers as they are the focus of the educational process in these educational institutions, so they must be taken care of and given all care, as the teacher of vocational education is a person with his capabilities and needs and it is capable of growth, but it is subject to stop also when neglected and the needs are linked to ability and desire At work, lack of tension and psychological burnout, the worker's satisfaction at work and his continued participation in the organization and an incentive to increase his productivity cannot be guaranteed unless what he perceives as his needs are identified, opportunities are created to satisfy them, and appropriate conditions are achieved to reduce stress and combustion and eliminate its causes.

This study also derives its importance from the fact that it is the first study within the limits of the two researchers knowledge, which is exposed to the phenomenon of psychological burnout among vocational education teachers compared to ordinary teachers in Jordan.

In addition, the results of this study, which is hoped to served these Rat schools and planners of the educational process and decision-makers in the field to identify the sources of burnout among teachers of vocational education enabling them to take appropriate decisions to confront this phenomenon and limit its spread and to address their underlying causes.

\section{Study Hypotheses}

This study is based on the following assumptions:

1. There is no statistical indication of the level of psychological burnout among vocational education teachers in Jordan. 
2 There are no differences that are statistically significant in psychological combustion between the levels of education teachers' professional and ordinary teachers in Jordan.

3 There are no differences with statistically significant between the sexes in the psychological combustion level of the education teachers professional and teachers and ordinary.

\section{Terminology of Study}

\section{Burnout:}

The two researchers know in this study that it is an internal psychological state that the individual feels as a result of work pressures and the excessive burdens placed on him, as it is the individual's response to psychological tension and professional pressures.

\section{Burnout level:}

The two researchers know in this study that it is the degree that a vocational education teacher obtains on the intensity of the dimensions of the Maslach and Jackson Burnout Scale used in this study, which consists of three dimensions:

- Emotional stress

- Sag feeling

- Lack of a sense of personal achievement

\section{Professional Education Teachers:}

They are all male and female teachers who teach vocational education from the fourth grade to the tenth grade in the Jordanian Ministry of Education schools.

\section{Curriculum}

The descriptive comparative approach is based on the study of the phenomenon or the feature as it exists in reality and is concerned with its description and expresses it in a qualitative and quantitative expression as the qualitative expression describes for us the phenomenon or the studied characteristic and explains its characteristics, while the quantitative expression gives us a numerical description that shows the amount or size of this feature. The two researchers relied on this approach in the current study by comparing the level of psychological burnout of vocational education teachers with the level of psychological burnout of ordinary teachers in Jordan.

\section{Study Population}

Since the study is aimed at comparing the level of combustion psychological among ordinary teachers and education teachers profession also the study communities are professional education teachers in the schools of the Ministry of Education of Jordan.

\section{Study Sample}

Formed the study sample of some ordinary teachers and some education teachers' professional workers in the Ministry of Education schools in Jordan, where the number of teachers and ordinary 80 teachers and 80 teachers of education teachers' professional and table the following number (1) shows the distribution of members of the sample.

Table 1: Distribution of the sample members.

\begin{tabular}{|l|l|l|l|}
\hline $\begin{array}{l}\text { Total } \\
\text { summation }\end{array}$ & $\begin{array}{l}\text { Vocational } \\
\text { education } \\
\text { teachers }\end{array}$ & $\begin{array}{l}\text { Ordinary } \\
\text { teachers }\end{array}$ & Sex \\
\hline 80 & 40 & 40 & Male \\
\hline 80 & 40 & 40 & Female \\
\hline 160 & 80 & 80 & $\begin{array}{l}\text { Total } \\
\text { summation }\end{array}$ \\
\hline
\end{tabular}

\section{Study Tool}

In this study, a burnout scale was used, which was prepared by the researchers, in light of its review of some previous studies that have occurred in this field, as well as a number of measures prepared in the field of psychological stress and burnout, as well as the use of the Maslash scale that was used in many studies that conducted in the field of psychological combustion because this measure is characterized by a high degree of honesty and consistency, but the researchers deliberately to another measure of the design of psychological combustion because many of the terms of this standard formulation is appropriate, but there searchers Qama design scale mainly based on many of the items mentioned in the scale Maslach and the scale used in this study is a seven-scale scale where (7) represents a very strong degree and (1) represents a very weak score, and to obtain the total score for an individual on the scale, his scores are collected on all the scale items and this scale includes two parts : 
(1) The first part includes general information such as gender, experience, educational level, stage of education at which he works, number of students in the class, and specialization.

(2) The second part includes the scale items, which are 35 items, distributed on each of three dimensions that constitute a total of psychological combustion:

- Emotional stress includes items (1, 3, 6, 8, 13, 14, 16, $20,23,25,26,29,32,33,35)$

- Sagging feelings and includes items (2, 5, 10, 11, 15, $22,24,27,28,34)$

- lack of a sense of accomplishment and includes items $(4,7,9,12,17,18,19,21,30,31)$

\section{Honesty and Stability of the Tool Used}

Honesty:

The display study tool in the image Alao Maly a group of arbitrators, the number often arbitrators from professors specialists from sections of Curriculum and Instruction and Measurement and Evaluation at Yarmouk University and the University of Jordan marketed asked the arbitrators to express their opinion on the safety of all the words of phrases measure and its suitability for the subject for, And making an amendment by deleting or adding expressions that need this, as well as giving the degree of safety of the scale, where the scale in its initial form consisted of 43 paragraphs, where the researchers modified and deleted some paragraphs on which $80 \%$ of the percentage of arbitrators agreed, as the scale in its final form consisted of 35 Paragraph.

Stability:

The two researchers applied the scale an hour before the end of school hours on a survey sample consisting of ten individuals after that they collected their scores, and then after 15 days had passed, they re-applied the scale to the same individuals and in the same period and after that their scores were collected for the researchers to ensure the stability of the scale that was It was calculated by Pearson's equation, where the scale was characterized by a high degree of stability, reaching (970).

\section{Application Procedures}

The study tool was applied to the study sample at separate times of the week and the school day, as the tool was applied to some members of the sample in the morning period from the beginning of the school day and others at the end of the school day, where the researchers asked the sample members to read the instructions on how to answer the paragraphs of the tool in every Accuracy then put a sign (x) in the appropriate place for each paragraph, and some of the teachers inquired about some of the items, and most of the sample members responded to the researchers in answering the scale items, after that the researchers collected questionnaires to analyze them statistically.

\section{Statistical Treatment Methods Used}

The two researchers processed the data using the statistical packages for the social sciences program (spss) through the computer, using the following statistical methods:

1. Means and standard deviations.

2. T-test to measure the differences between the averages and their significance.

3. T-test for one group.

\section{Results}

\subsection{Results of the First Hypothesis}

To test the validity of the first hypothesis, which relates to the lack of statistical significance on the level of psychological burnout among vocational education teachers, using the test $(\mathrm{T})$ to calculate the significance of the level of psychological burnout as shown in Table 2.

Table 2: The level of psychological burnout among teachers of professional education.

\begin{tabular}{|l|l|l|l|l|l|}
\hline $\begin{array}{l}\text { Indication } \\
\text { level }\end{array}$ & $\begin{array}{l}\text { Values } \\
\mathbf{t}\end{array}$ & $\begin{array}{l}\text { Standard } \\
\text { deviation }\end{array}$ & SMA & $\begin{array}{l}\text { The } \\
\text { number } \\
\text { of the } \\
\text { sample }\end{array}$ & Variables \\
\hline 0.000 & 452,66 & 3471, & $\begin{array}{l}3 . \\
345\end{array}$ & 80 & $\begin{array}{l}\text { Vocational } \\
\text { education } \\
\text { teachers }\end{array}$ \\
\hline
\end{tabular}

It is evident from the previous Table 2, which the results indicate that there is a statistical indication in the level of psychological burnout among vocational education teachers, as it was found that the degree of psychological burnout among vocational education teachers was medium and this result is in agreement 
with the results of many studies conducted on teachers of vocational education as a study Adnan Al-Farah (2019) and the study of Zaidan Al-Sartawi (2018). This may be due to the fact that these studies relied on the Maslach scale, which was characterized by a high degree of validity and consistency, and it is the same scale that the researchers relied upon designing the scale of the current study.

\subsection{Results of the Second Hypothesis}

To test the validity of the second hypothesis and concerning then on - the existence of differences between the samples of the study on the psychological variable combustion used researchers test $(\mathrm{t})$ to calculate the differences between the sample and significance as shown in Table 3.

Table 3: The differences between the averages of the two study samples on the burnout level variable.

\begin{tabular}{|l|l|l|l|l|l|}
\hline $\begin{array}{l}\text { Indication } \\
\text { level }\end{array}$ & $\begin{array}{l}\text { Values } \\
\mathbf{t}\end{array}$ & $\begin{array}{l}\text { Standard } \\
\text { deviation }\end{array}$ & SMA & $\begin{array}{l}\text { The } \\
\text { number of } \\
\text { the sample }\end{array}$ & Variables \\
\hline 0.043 & 16. & 2567, & 3.6573 & 80 & $\begin{array}{l}\text { Ordinary } \\
\text { teachers }\end{array}$ \\
& 435 & 2987, & 3.5998 & 80 & $\begin{array}{l}\text { Vocational } \\
\text { education } \\
\text { teachers }\end{array}$ \\
\hline
\end{tabular}

It is evident from Table which the results indicate that there are statistically significant differences between vocational education teachers and ordinary teachers in the level of psychological burnout, as it was found that the average of vocational education teachers is higher than the average of ordinary teachers, and the standard deviation of vocational education teachers is higher than the standard deviation of teachers. Ordinary and this result show that professional education teachers suffer from psychological burnout.

\subsection{Results of the Third Hypothesis}

To test the validity of the third hypothesis, which relates to the differences between the two study samples on the gender variable, the researchers used the $(\mathrm{T})$ test to calculate the differences between the two sample members and their significance, as shown in Table 4.

It can be seen from the Table 4 which results indicate a lack of statistically significant gender differences in the level of combustion psychological among education teachers professional and ordinary teachers indicating no effect of sex in the level of combustion psychological and this Alan Result was not expected by the researchers' system areas to prepare for the psychological among females Where the results of the current study are in agreement with the Al-Wabli study (2018) and the study of Muhammad (2019), while the results of the current study differed with the results of the study carried out by Askar, (2019) whose results showed that male teachers are more exposed to the phenomenon of psychological burnout than female teachers, while the results showed An interview and safety study (2019): There are significant differences in the level of psychological burnout in favor of female teachers.

Table 4: The differences between the two study samples on the sex variable.

\begin{tabular}{|l|l|l|l|l|l|l|}
\hline $\begin{array}{l}\text { Indication } \\
\text { level }\end{array}$ & $\begin{array}{l}\text { Values } \\
\mathbf{t}\end{array}$ & $\begin{array}{l}\text { Standard } \\
\text { deviation }\end{array}$ & SMA & $\begin{array}{l}\text { The } \\
\text { number } \\
\text { of the } \\
\text { sample }\end{array}$ & Sex & Variables \\
\hline 421, & \multirow{2}{*}{598,} & 2456, & 2314,3 & 40 & Female & $\begin{array}{l}\text { Ordinary } \\
\text { teachers }\end{array}$ \\
\cline { 4 - 7 } 103, & \multirow{2}{*}{213,} & 3457, & 7693,3 & 40 & Males & \\
\cline { 4 - 7 } & & & 8231,3 & 40 & Female & $\begin{array}{l}\text { Education } \\
\text { teachers }\end{array}$ \\
\hline
\end{tabular}

\section{The Recommendations:}

In light of the results of the previous study, the researchers recommend the following:

1. Do some studies the survey aims to know and investigate the causes and conditions that create a feeling of psychological burnout with vocational education teachers.

2. Training of specialized professional cadres to be able to provide the necessary consultations to deal with work stress and psychological burnout. 
3. Design necessity and the implementation of some preventive programs that help workers in the field of vocational education and vocational education to achieving better adaptation to the conditions of work difficulties.

4. Ensure suitable workloads And the tasks assigned to the capabilities and qualifications of vocational education and vocational education teachers to avoid their feelings Helplessness and lack of a sense of accomplishment.

\section{References}

Askar, A. (2019). Exposure of secondary school teachers in the State of Kuwait to the phenomenon of psychological burnout. The Educational Journal, Kuwait, 3(10), 9.

Al-Battal, Z. M. (2018). Psychological burnout for the special education teacher. Research presented in counseling seminar Psychological and professional for a better quality of life for people with special needs, University Persian Gulf, Bahrain.

Al-Dairi, Mahmoud bin Muhammad Ibrahim (2017). Understanding psychological stress and its relationship to some personality traits and some demographic variables for a sample of teachers. In Dammam, An unpublished master's thesis, College of Education, University of Bahrain.

Al-Farah, Adnan. (2019). Psychological burnout among those working with people with special needs in the State of Qatar. Search presented in a symposium on psychological and professional counseling for a better quality of life for people with disabilities Special Needs, Arabian Gulf University, Bahrain.

Al-Jamali, F. A. B. (2019). Burnout levels of teachers with special needs. Arabic studies in the science of the same, 2(1), S151-S211.

Al-Hamr, P. ( 2018 ). A study of the psychological burnout level of special education teachers compared to ordinary teachers in the Kingdom of Bahrain Study of a graduation project, College of Education, University of Bahrain.

Al-Musharraf, F. A. W. (2019) . Burnout Among Female Faculty of King Saud University. Journal of Gulf and Arabian Peninsula Studies, 28(105), 193.

Al-Qaryouti, I., \& Al-Khatib, F. (2018). Psychological burnout among a sample of teachers of ordinary students and those with special needs in Jordan, College of Education Journal, United Arab Emirates University, Twenty-first Year, Issue (23).
Al-Rafi'i, Y., \& Al-Qadhi, M. (2019). Psychological burnout levels among faculty members at Teachers College in Abha in light of some variables, Umm Al-Qura University. Journal of Educational and Psychological Sciences, 2(2).

Al-Rashidi, H. T. (2018) . Psychological stress, its nature, theories, programs for self-help in its treatment. The Anglo Egyptian Library.

Al-Sheikh, D. (2017) . Psychology of the relationship between occupational satisfaction and psychological burnout. Arab Journal of Education, 22(2), 9.

Al- Shuyoukh, L. (2016). The teacher's psychological burnout and its relationship to the trend towards the teaching profession. Unpublished Master's degree, Arab Open Academy in Denmark, College of Arts and Education.

Al-wabily, S. (2018). Combustion and psychological levels among teachers of general education in Mecca pain vine in light of Masla scale expressed. Educational Research Center, Umm Al-Qura University, Makkah.

Al-Zahrani, N. (2018). Psychological burnout and its relationship to some personality traits among women workers with special needs, unpublished master's thesis, College of Education, Umm Al-Qura University, Saudi Arabia.

Magableh, N. Y., \& Salameh, K. M. (1993). Study of the Burnout Phenomenon of a Sample of Jordanian Teachers through a Number of Variables. Journal of Damascus University, 9(33, 34), 179 - 214.

Muhammad, Y. A. F. (2019) . The psychological pressure of teachers and their counseling needs. Journal of the Center for Educational Research, 8(15), 195.

Rana, N., and Khawleh, Y. (2017) . Sources of psychological burnout among teachers of mentally handicapped students in Yemen. Journal of the Center for Educational Research, 10(20), 97.

Isa, M. (2015). Professional compatibility and its relationship to psychological burnout among Riyadh teachers. The Educational Journal, 9(34),

Sartawi, Z. (2018). Psychological burnout and its sources for specialeducation teachers: A field study. Journal of the Faculty of Education, Ain Shams University, 21(1), 57-96.

Zaghoul, R. (2019). Psychological burnout among male and female teachers and its relationship to their perception of the Karak pattern from the teachers' point of view. Mu'ta Research and Studies Series - Human and Social Sciences Series, 18(6), 243. 


\section{司 \\ CHITKARA}

\section{Issues and Ideas in Education}

Chitkara University, Saraswati Kendra, SCO 160-161, Sector 9-C, Chandigarh, 160009, India

Copyright: [C 2021 Elham Mahmoud Rababa and Mohammad Omar AL-Momani] This is an Open Access article published in Issues and Ideas in Education (Issues Ideas Educ.) by Chitkara University Publications. It is published with a Creative Commons Attribution- CC-BY 4.0 International License. This license permits unrestricted use, distribution, and reproduction in any medium, provided the original author and source are credited. 